\title{
Produção de Forragem e Rentabilidade da Recria de Novilhos de Corte em Área de Várzea ${ }^{1}$
}

\section{Gelson dos Santos Difante ${ }^{2}$, Enio Marchezan ${ }^{3}$, Marta Gomes da Rocha ${ }^{4}$, Tommi Segabinazzi ${ }^{5}$, Silvio Carlos Cazarotto Villa ${ }^{5}$, Simone Michelon ${ }^{5}$}

\begin{abstract}
RESUMO - O experimento foi realizado em 2000 (Ano 1) e 2001 (Ano 2), em várzea sistematizada, com o objetivo de comparar o uso de doses de adubação nitrogenada em cobertura, associadas a níveis de suplementação energética, sobre os teores de proteína bruta, digestibilidade in vitro da matéria orgânica e produção de forragem, produção animal e rentabilidade. Os tratamentos aplicados no Ano 1 foram: novilhos em pastagem cultivada de azevém (Lolium multiflorum Lam.) + $300 \mathrm{~kg} / \mathrm{ha}$ de nitrogênio (N), recebendo suplementação com grão de milho moído a $0,8 \%$ do peso vivo (PV)/dia $(300 \mathrm{~N}+0,8 \mathrm{~S})$; novilhos em pastagem de azevém $+200 \mathrm{~kg} / \mathrm{ha}$ de $\mathrm{N}$, recebendo suplementação com grão de milho moído a $0,4 \%$ do PV/dia $(200 \mathrm{~N}+0,4 \mathrm{~S})$; e novilhos em pastagem de azevém + $100 \mathrm{~kg} / \mathrm{ha}$ de $\mathrm{N}$, sem suplementação $(100 \mathrm{~N}+0,0 \mathrm{~S})$. No Ano 2: novilhos em pastagem de azevém + $230 \mathrm{~kg} / \mathrm{ha}$ de N, recebendo suplementação com grão de milho moído a 1,0\% do PV/dia (230N+1,0S); novilhos em pastagem de azevém + $155 \mathrm{~kg} / \mathrm{ha}$ de $\mathrm{N}$, recebendo suplementação com grão de milho moído a $0,5 \%$ do PV/dia $(155 \mathrm{~N}+0,5 \mathrm{~S})$; novilhos em pastagem de azevém $+80 \mathrm{~kg} / \mathrm{ha}$ de $\mathrm{N}$, sem suplementação ( $80 \mathrm{~N}+0,0 \mathrm{~S})$. Foram utilizados novilhos de corte em pastagem sob lotação contínua e carga variável. A taxa de acúmulo de massa seca não diferiu entre os níveis de $\mathrm{N}$ e de suplementação utilizados. O ganho de peso animal por hectare foi maior quando se utilizaram as maiores doses de $\mathrm{N}$ e suplementação. A menor utilização de $\mathrm{N}$ e a ausência de suplementação em 2000 ocasionaram a maior renda líquida. Em 2001, qualquer nível de insumo utilizado apresentou renda líquida negativa. O aumento das doses de adubação nitrogenada em cobertura, associado a diferentes níveis de suplementação energética, embora tenha proporcionado acréscimo na taxa de lotação, não afetou a taxa de produção de massa seca e a qualidade da forragem, resultando em menor renda líquida.
\end{abstract}

Palavras-chave: azevém, grão de milho, nitrogênio, renda líquida, suplementação

\section{Production of Forage and Economic Return in Italian Ryegrass Pasture under Grazing with Beef Cattle in Lowland Area}

\begin{abstract}
The experiment was carried out from 2000 (Year 1) to 2001 (Year 2), in a leveled lowland, to compare the effect of nitrogen levels and energy supplementation levels on the herbage crude protein, in vitro organic matter digestibility and production, animal production and profit. The treatments used in Year 1 were: Italian ryegrass cultivated pasture (Lolium multiflorum Lam.) plus $300 \mathrm{~kg}$.ha of nitrogen $(\mathrm{N})$ and supplementation with ground corn grain at .8\% LW/day (300N+.8S); Italian ryegrass pasture plus 200 kg.ha $\mathrm{N}$ and supplementation with ground corn grain at $.4 \% \mathrm{LW} / \mathrm{day}$; and Italian ryegrass pasture plus $100 \mathrm{~kg} . \mathrm{ha} \mathrm{N}$, without supplementation $(100 \mathrm{~N}+.0 \mathrm{~S})$. In Year 2, the treatments were: Italian ryegrass pasture plus $230 \mathrm{~kg}$.ha $\mathrm{N}$ and supplementation with ground corn grain at $1.0 \% \mathrm{LW} /$ day $(230 \mathrm{~N}+1.0 \mathrm{~S})$; Italian ryegrass pasture plus $155 \mathrm{~kg}$.ha N and supplementation with ground corn grain at $0.5 \% \mathrm{LW} /$ day $(155 \mathrm{~N}+.5 \mathrm{~S})$; and Italian ryegrass pasture plus $80 \mathrm{~kg}$.ha $\mathrm{N}$, without supplementation $(80 \mathrm{~N}+.0 \mathrm{~S})$. Beef steers under continuous stocking grazing, with variable stocking rate, were used. Dry matter accumulation rate did not show difference among $\mathrm{N}$ and supplementation levels. The live weight gain per hectare was higher when higher nitrogen and supplementation levels were used. In 2000, the treatment with the smaller N level and no supplementation resulted in positive net income. In 2001, all treatments showed negative net income. The increasing nitrogen levels with different energy supplementation levels, although increased the stocking rate, did not affect dry matter yield rate and forage quality, resulting in smaller net income.
\end{abstract}

Key Words: corn grain, net income, nitrogen ryegrass, supplementation

\footnotetext{
${ }^{1}$ Parte da dissertação de Mestrado do primeiro autor.

${ }^{2}$ Zootecnista. MSc. em Agronomia, Acadêmico do Curso de Doutorado em Zootecnia, Universidade Federal de Viçosa. Viçosa. Bolsista CNPq. E.mail: gdifante@hotmail.com. Autor para correspondência.

${ }^{3}$ Eng $^{\circ}$. Agro‥, Dr Professor do Depto de Fitotecnia, Universidade Federal de Santa Maria, UFSM. Santa Maria, RS, Campus Camobi, CEP: 97119-900. Pesquisador CNPq. E.mail: emarch@ccr.ufsm.br

${ }^{4}$ Eng $^{\circ}$. Agro ${ }^{\circ}$., Dra. Professora do Depto de Zootecnia, Universidade Federal de Santa Maria, UFSM. Santa Maria, RS, Campus, Camobi CEP: 97119-900. E.mail:mrocha@ccr.ufsm.br

${ }^{5}$ Acadêmico do curso de Agronomia da UFSM.
} 


\section{Introdução}

O arroz irrigado é a principal cultura utilizada nas áreas de várzea, onde predominam solos hidromórficos e deficiência de drenagem. É uma atividade econômica consolidada, mas, com o decorrer dos anos, tem apresentado redução de renda ao orizicultor. Além disso, o cultivo contínuo de áreas com arroz vem agravando problemas com o aumento de pragas, como a bicheira da raiz do arroz e o percevejo do colmo, ou de doenças, como a brusone, além do aumento na freqüência de plantas invasoras, destacando-se o arroz vermelho. No Rio Grande do Sul, em áreas de várzea, a pecuária de corte é uma opção complementar ao cultivo sustentável do arroz. No entanto, é necessário conhecer o retorno econômico do cultivo de pastagens neste ecossistema, especialmente no período hibernal, quando ocorrem freqüentes excessos de água no solo.

Saibro \& Silva (1999) observaram que o azevém anual é adaptado à área de várzea, apresentando altos rendimentos de forragem e bom valor nutritivo, quando a planta está bem nutrida e adubada com dose anual de nitrogênio entre 80 e $100 \mathrm{~kg} / \mathrm{ha}$. As leguminosas, por sua vez, mostraram-se mais exigentes, necessitando de melhores condições de fertilidade e drenagem. Também avaliando a produção de plantas forrageiras de estação fria em solos hidromórficos, durante três anos, Gomes \& Reis (1999) destacaram o alto potencial de produção do azevém. Coelho \& Reis (2000) confirmaram estas informações e constataram que o azevém foi a gramínea que apresentou maior produtividade de forragem no período de julho a dezembro.

A utilização da adubação nitrogenada em pastagem cultivada pode ser uma ferramenta para o incremento na produção de massa seca e, conseqüentemente, para a produção animal, por meio do aumento da capacidade de suporte da pastagem e da produção animal por hectare (Marino et al., 1996).

Mazzanti et al. (1997), utilizando diferentes doses de nitrogênio $(\mathrm{N})$ em pastagem cultivada de azevém anual, constataram que a aplicação de $100 \mathrm{~kg} / \mathrm{ha}$ de $\mathrm{N}$ praticamente duplicou a taxa de acúmulo da forragem em comparação com a área sem utilização de N. Dados semelhantes foram observados por Lupatini et al. (1998), que, aplicando $150 \mathrm{~kg} / \mathrm{ha}$ de $\mathrm{N}$ em misturas de plantas forrageiras de inverno, observaram aumento médio de $122 \%$ na taxa de acúmulo de massa seca da pastagem e, quando se utilizaram
$300 \mathrm{~kg} /$ ha de N, possibilitaram lotação animal máxima de $1865 \mathrm{~kg} / \mathrm{ha}$ de peso vivo.

Uma prática adotada como medida de segurança e de aumento do potencial de produção é a suplementação alimentar no campo, para dar continuidade à oferta de alimento em condições de déficit forrageiro, aumentar a produção e a lotação durante o ciclo produtivo e, também, aumentar a renda, dependendo do custo e da efetividade do alimento (Santini \& Elizalde, 1993).

Kloster \& Amigone (1999) observaram avanço de 19,3 e $38,8 \%$ na produção de peso vivo (PV)/ha, em pastagem cultivada de inverno, ao suplementar com grão de milho seco, nos níveis de 0,5 e $1 \%$ do peso vivo, respectivamente. $\mathrm{O}$ aumento da lotação animal foi proporcional à quantidade de grão empregado em cada nível de suplementação. Assmann et al. (1999), utilizando novilhos Charolês em pastagem de azevém e trevo branco, suplementados com milho macerado na proporção de 0,5 e $1 \%$ do PV, verificaram que a suplementação elevou o desempenho individual e a produção por hectare em aproximadamente 30 e $25 \%$, respectivamente, em relação ao grupo sem suplementação.

A utilização de altos níveis de insumos, como nitrogênio e suplementos, assegura bons resultados biológicos no desempenho de bovinos em pastejo e sempre cria um espaço para o questionamento sobre sua economicidade. Em áreas de várzeas, onde o solo é mal drenado, esta preocupação é ainda maior, pois os níveis de resposta biológica são diferentes dos dados obtidos em solos bem drenados. Neste caso, reveste-se de importância a análise do retorno econômico, de acordo com o nível tecnológico empregado no processo de produção animal.

O objetivo neste trabalho foi comparar o uso de doses de adubação nitrogenada em cobertura associadas a níveis de suplementação energética, sobre parâmetros de qualidade e produção de forragem, produção animal e rentabilidade, baseando-se na hipótese que a adubação nitrogenada em cobertura, associada aos níveis de suplementação energética influencia estes parâmetros.

\section{Material e Métodos}

O experimento foi conduzido em área experimental do Departamento de Fitotecnia da Universidade Federal de Santa Maria, em solo classificado como Planossolo Hidromórfico eutrófico arênico. 
A área experimental utilizada foi sistematizada em 1996 com um desnível de aproximadamente $0,06 \%$ e foi dividida em seis unidades experimentais de 0,5 ha. Em cada unidade, foram construídos drenos superficiais com $0,12 \mathrm{~m}$ de largura e $0,20 \mathrm{~m}$ de profundidade, no sentido da declividade, para auxiliar a drenagem superficial. Em 1997, foi realizada aplicação de calcário visando elevar o $\mathrm{pH}$ do solo a 5,5 pelo índice SMP, tendo sido cultivada com forrageiras de inverno até o início deste experimento.

A implantação da pastagem no Ano 1, foi realizada dia 07/04/2000, quando foram semeados a lanço $40 \mathrm{~kg} / \mathrm{ha}$ de azevém. A área experimental foi previamente dessecada com dose de 1,8 litros de glifosate e 0,5\% de óleo mineral por hectare. Em 11/05/2000, o azevém foi ressemeado, utilizando-se $25 \mathrm{~kg} / \mathrm{ha}$ de sementes, em decorrência da baixa população de plantas observada.

Os tratamentos foram: novilhos em pastagem cultivada de azevém (Lolium multiflorum Lam.) + $300 \mathrm{~kg} / \mathrm{ha}$ de nitrogênio $(\mathrm{N})$, recebendo suplementação com grão de milho moído a $0,8 \%$ do peso vivo (PV)/ dia $(300 \mathrm{~N}+0,8 \mathrm{~S})$; os novilhos em pastagem cultivada de azevém + $200 \mathrm{~kg} / \mathrm{ha}$ de $\mathrm{N}$, recebendo suplementação com grão de milho moído a $0,4 \%$ do $\mathrm{PV} /$ dia $(200 \mathrm{~N}+0,4 \mathrm{~S})$; novilhos em pastagem cultivada de azevém $+100 \mathrm{~kg} / \mathrm{ha}$ de $\mathrm{N}$, sem suplementação $(100 \mathrm{~N}+0,0 \mathrm{~S})$.

A adubação de base foi realizada a lanço, após a emergência do azevém, nas doses recomendadas pela Comissão de Fertilidade do solo - RS/SC (1999), de acordo com análise química do solo na profundidade de $0-10 \mathrm{~cm}$, que apresentou os seguintes resultados: Ano 1: $\mathrm{pH}$ em $\mathrm{H}_{2} \mathrm{O}=6,0, \mathrm{Al}^{+++}=0,0 \mathrm{cmol} / \mathrm{dm}^{3}$, $\mathrm{Ca}^{++}=7,6 \mathrm{cmol} / \mathrm{dm}^{3}, \mathrm{Mg}^{++}=4,7 \mathrm{cmol} / \mathrm{dm}^{3}$, $\mathrm{CTC}=11,5 \mathrm{cmol} / \mathrm{dm}^{3}, \mathrm{~K}^{+}=50,3 \mathrm{mg} / \mathrm{dm}^{3}, \mathrm{P}=10,5 \mathrm{mg} / \mathrm{dm}^{3}$ e $\mathrm{MO}=2,2 \%$. Ano $2: \mathrm{pH}$ em $\mathrm{H}_{2} \mathrm{O}=5,9, \mathrm{Al}^{+++}=$ $0,0 \mathrm{cmol} / \mathrm{dm}^{3}, \mathrm{Ca}^{++}=7,1 \mathrm{cmol} / \mathrm{dm}^{3}, \mathrm{Mg}^{++}=3,0 \mathrm{cmol} / \mathrm{dm}^{3}$, $\mathrm{CTC}=10,1 \mathrm{cmol} / \mathrm{dm}^{3}, \mathrm{~K}^{+}=37,0 \mathrm{mg} / \mathrm{dm}^{3}, \mathrm{P}=10,5 \mathrm{mg} / \mathrm{dm}^{3}$ e $\mathrm{MO}=2,3 \%$.

A adubação nitrogenada foi aplicada a lanço, dividida em cinco aplicações, realizadas aos 62, 100, 121, 157 e 192 dias após a emergência do azevém. As aplicações foram na forma de uréia, sendo a primeira igual para todos os tratamentos, com 22,5 kg/ha de N. Na segunda, foram aplicados 90, 58,5 e 22,5 kg/ha de $\mathrm{N}$ para os tratamentos $300 \mathrm{~N}+0,8 \mathrm{~S}, 200 \mathrm{~N}+0,4 \mathrm{~S}$ e $100 \mathrm{~N}+0,0 \mathrm{~S}$, respectivamente. Na terceira e quarta, foram utilizadas as mesmas quantidades de uréia, sendo 62,40 e $27,5 \mathrm{~kg} / \mathrm{ha}$ de $\mathrm{N}$, respectivamente, para os tratamentos $300 \mathrm{~N}+0,8 \mathrm{~S}, 200 \mathrm{~N}+0,4 \mathrm{~S}$ e $100 \mathrm{~N}+0,0 \mathrm{~S}$. A quinta aplicação foi realizada apenas nos tratamentos $300 \mathrm{~N}+0,8 \mathrm{~S}$ e $200 \mathrm{~N}+0,4 \mathrm{~S}$ nas quantidades de 63 e $40 \mathrm{~kg} / \mathrm{ha}$ de $\mathrm{N}$, respectivamente. No tratamento $100 \mathrm{~N}+0,0 \mathrm{~S}$, a dose determinada foi atingida na quarta aplicação.

No Ano 2, a implantação da pastagem foi realizada dia 03/04/2001, sendo semeados a lanço $40 \mathrm{~kg} / \mathrm{ha}$ de azevém, na área previamente roçada, para diminuir a competição das espécies nativas no início do estabelecimento do azevém. No dia 18/04/2001, foram semeados o azevém $40 \mathrm{~kg} / \mathrm{ha}$ de semente de azevém, para aumentar a população de plantas da espécie cultivada.

Os tratamentos utilizados foram: novilhos em pastagem cultivada de azevém $+230 \mathrm{~kg} / \mathrm{ha}$ de $\mathrm{N}$, recebendo suplementação com grão de milho moído e $1,0 \%$ do $\mathrm{PV} /$ dia $(230 \mathrm{~N}+1,0 \mathrm{~S})$; novilhos em pastagem cultivada de azevém $+155 \mathrm{~kg} / \mathrm{ha}$ de $\mathrm{N}$, recebendo suplementação com grão de milho moído a $0,5 \%$ do $\mathrm{PV} /$ dia $(155 \mathrm{~N}+0,5 \mathrm{~S})$; novilhos em pastagem cultivada de azevém $+80 \mathrm{~kg} / \mathrm{ha}$ de $\mathrm{N}$, sem suplementação $(80 \mathrm{~N}+0,0 \mathrm{~S})$.

A adubação de base foi realizada a lanço, após a emergência do azevém, na dose de reposição recomendada pela Comissão de Fertilidade do solo - RS/SC (1999), de acordo com a análise química do solo feita na profundidade de $0-10 \mathrm{~cm}$. A adubação nitrogenada foi aplicada a lanço e em cobertura, na forma de uréia, dividida em quatro aplicações aos 55, 110, 133 e 180 dias após a emergência do azevém. A primeira aplicação foi igual para todos os tratamentos, utilizando-se $20 \mathrm{~kg} / \mathrm{ha}$ de $\mathrm{N}$; na segunda, terceira e quarta aplicações, foram utilizados 70,45 e $20 \mathrm{~kg} / \mathrm{ha} \mathrm{N}$, para os tratamentos $230 \mathrm{~N}+1,0 \mathrm{~S}, 155 \mathrm{~N}+0,5 \mathrm{~S}$ e $80 \mathrm{~N}+0,0 \mathrm{~S}$, respectivamente. A grande incidência de chuvas nos meses de julho, setembro e outubro impossibilitou o uso das mesmas dosagens de adubação nitrogenada do ano anterior, pois o solo permanecia por longos períodos com umidade excessiva, impedindo a aplicação do nitrogênio.

Os animais experimentais foram bovinos machos castrados da raça Charolês e suas cruzas com Nelore, com média de oito a dez meses de idade. Foi utilizado o método de pastejo com lotação contínua e carga variável. Os animais passaram por um período de adaptação de 12 dias, em pastagem semelhante àquela utilizada no experimento, com suplementação diária, para adaptação à nova dieta e ao manejo. $\mathrm{O}$ período de pastejo foi de 15/07 a 03/11 de 2000 e de 
30/07 a 23/10 de 2001, correspondendo a 110 e 85 dias, respectivamente.

A disponibilidade de forragem da pastagem foi avaliada pela técnica de dupla amostragem (Gardner, 1986) a cada 28 dias; em cada unidade experimental cinco amostras foram cortadas rente ao solo $\left(0,25 \mathrm{~m}^{2} /\right.$ amostra) e 25 avaliadas visualmente. A forragem proveniente das amostras cortadas foram secas em estufa de ventilação forçada a $65^{\circ} \mathrm{C}$, para determinação da matéria seca da forragem.

A taxa de acúmulo de massa seca diária (TAMS) foi determinada utilizando a "técnica do triplo emparelhamento" (Moraes et al., 1990), a cada 28 dias, com o uso de três gaiolas de exclusão ao pastejo por unidade experimental.

A produção total de massa seca foi calculada pela média ponderada da taxa de acumulação diária dos diferentes períodos multiplicada pelos dias de pastejo. A massa de forragem na data de entrada dos animais foi somada a estes valores.

A simulação de pastejo foi realizada a cada 28 dias, durante cada período experimental, coletando-se amostra representativa da forragem consumida pelos animais. Foam observados o animal em pastejo, a altura, espécie e parte da planta que estava sendo consumida, seqüencialmente, coletando-se manual a forragem julgada semelhante àquela selecionada pelo animal. As amostras foram secas em estufa a $65^{\circ} \mathrm{C}$ e processadas em moinho tipo Willey com peneira de malha de $1 \mathrm{~mm}$, para análises laboratoriais. Foi determinado o teor de nitrogênio total das amostras parcialmente secas da simulação de pastejo, pelo método MicroKjeldahl (AOAC, 1984). A proteína bruta foi obtida pela multiplicação do teor de nitrogênio total pelo fator 6,25 .

Os cálculos de custos foram feitos em planilhas eletrônicas do programa Excel, utilizando os preços médios dos insumos nos últimos dez anos. Foram considerados custos fixos, depreciação de máquinas e implementos, mão-de-obra, cercas, calcário, herbicidas, azevém, pulverização, construção de drenos, semeadura e adubação de base. O custo obtido em função dos tratamentos foi considerado variável e foi composto pelo suplemento e seu fornecimento, fertilizante e adubação nitrogenada de cobertura, sal e vermífugos. O custo total de cada tratamento foi composto pelos custos fixos, custos variáveis, custo de oportunidade da terra, custo do financiamento, custo de oportunidade dos novilhos e imposto territorial rural (ITR).
Para o cálculo da renda bruta, foi considerado o preço médio do kg de PV do bezerro no mês de novembro de cada ano. A receita líquida foi obtida pela diferença entre a renda bruta total, calculada a partir do valor da comercialização da carne, expressa em ganho de peso vivo/ha, e o custo total da pastagem de azevém com ou sem suplementação.

O delineamento experimental foi o inteiramente casualizado com duas repetições de área. No Ano 1, o arranjo fatorial foi $3 \times 4$, sendo que os três tratamentos foram $300 \mathrm{~N}+0,8 \mathrm{~S}, 200 \mathrm{~N}+0,4 \mathrm{~S}$ e $100 \mathrm{~N}+0,0 \mathrm{~S}$ e os quatro períodos constaram das avaliações realizadas aos 28(15/07-11/08), 56(12/08-08/09), 84(09/09-06/10) e $112(07 / 10-03 / 11)$ dias. No Ano 2, o arranjo fatorial foi $3 \times 3$, sendo que os três tratamentos foram $230 \mathrm{~N}+1,0 \mathrm{~S}$, $155 \mathrm{~N}+0,5 \mathrm{~S}$ e $80 \mathrm{~N}+0,0 \mathrm{~S}$ e os três períodos constaram das avaliações realizadas aos 31 (30/07-30/08), 59 (31/08-27/09), 87 (28/09-26/10) dias. Os parâmetros avaliados, com exceção dos dados da análise econômica, foram submetidos à análise de variância, por intermédio do General Linear Models Procedure (Proc GLM). As diferenças entre tratamentos foram comparadas pelo teste Tukey $(\mathrm{P} \leq 0,05)$, utilizando-se o pacote estatístico SAS versão 6.08 (1997). O modelo matemático foi:

$$
\mathrm{Y}_{\mathrm{ijk}}=\mu+\mathrm{T}_{\mathrm{i}}+\mathrm{P}_{\mathrm{j}}+(\mathrm{TP})_{\mathrm{ij}}+\mathrm{E}_{\mathrm{ijk}}
$$

em que: $\mathrm{Y}_{\mathrm{ijk}}=$ variáveis dependentes; $\mu=$ média de todas as observações; $\mathrm{T}_{\mathrm{i}}=$ efeito de tratamento; $\mathrm{P}_{\mathrm{j}}=$ efeito do j-ésimo período; $(\mathrm{TP})_{\mathrm{ij}}=$ interação entre o i-ésimo tratamento e o j-ésimo período; $\mathrm{E}_{\mathrm{ijk}}=$ erro experimental residual (erro b).

\section{Resultados e Discussão}

A taxa de acúmulo de massa seca (Tabela 1) não diferiu entre tratamentos e também não apresentou interação entre tratamento e período $(\mathrm{P}>0,05)$, nos dois anos avaliados. Houve, no entanto, diferença entre períodos $(\mathrm{P} \leq 0,05)$ no primeiro ano, de modo que o último período avaliado apresentou crescimento negativo, o que pode ser explicado, em parte, pela senescência do azevém que se encontrava no final do ciclo, pela baixa insolação ocorrida no período e pela pequena contribuição das espécies nativas. A diminuição da taxa de acúmulo de massa seca, no decorrer do período de pastejo, também foi verificada por Roso et al. (1999), utilizando diferentes misturas de gramíneas. Soares (1999), utilizando doses de 0 a $450 \mathrm{~kg} / \mathrm{ha}$ de 
Tabela 1 - Taxa de acúmulo de massa seca (TAMS, kg/ha/dia de MS) e produção de forragem (PF, kg/ha de MS) para bovinos de corte recebendo diferentes níveis de suplementação energética, em pastagem de azevém submetida a doses de nitrogênio, sob lotação contínua

Table 1 - Dry matter accumulation rate (DMAR, $\mathrm{kg} / \mathrm{ha} /$ day DM) and forage yield (FY, $\mathrm{kg} / \mathrm{ha} D M$ ) of beef steers fed diets with different levels of energy supplementation, grazing a ryegrass pasture with different nitrogen levels, under continuous stocking rate

\begin{tabular}{|c|c|c|c|c|c|}
\hline \multirow[t]{3}{*}{$\begin{array}{l}\text { Variável } \\
\text { Variable } \\
\end{array}$} & \multicolumn{4}{|c|}{$\begin{array}{c}\text { Período } \\
\text { Period }\end{array}$} & \\
\hline & \multicolumn{4}{|c|}{2000} & \\
\hline & $15 / 07-11 / 08$ & $12 / 08-08 / 09$ & 09/09-06/10 & 07/10-03 & $\begin{array}{l}\text { Média } \\
\text { Mean }\end{array}$ \\
\hline TAMS (DMAR) & $55,77 \mathrm{a}^{1}$ & $32,96 a$ & $40,19 a$ & $-2,83 b$ & 31,52 \\
\hline \multirow[t]{3}{*}{$\mathrm{PF}(F Y)$} & $1561 \mathrm{a}$ & $923 a$ & $1125 \mathrm{a}$ & $-143 b$ & 866,5 \\
\hline & \multicolumn{4}{|c|}{2001} & \\
\hline & $30 / 07-30 / 08$ & $31 / 08-27 / 09$ & $28 / 09-26 / 10$ & $\begin{array}{l}\text { Média } \\
\text { Mean }\end{array}$ & \\
\hline TAMS (DMAR) & $31,66 \mathrm{a}$ & $33,64 a$ & $50,90 \mathrm{a}$ & 38,73 & \\
\hline $\mathrm{PF}(F Y)$ & $981 \mathrm{a}$ & $942 a$ & $1425 \mathrm{a}$ & 1116 & \\
\hline
\end{tabular}

${ }^{1}$ Médias seguidas de letras diferentes na linha diferem $(\mathrm{P}<0,05)$ entre si pelo teste Tukey.

${ }^{1}$ Means followed by different letters, within a row, differ $(P<.05)$ by Tukey test.

nitrogênio, encontrou comportamento quadrático para a taxa de acúmulo de MS, nas médias dos níveis de $\mathrm{N}$ na mistura de azevém com triticale. Lupatini et al. (1998), por sua vez, avaliando doses de 0 a $300 \mathrm{~kg} / \mathrm{ha}$ de $\mathrm{N}$ em pastagem de aveia e azevém, observaram comportamento linear para a taxa de acúmulo de MS.

A ausência de resposta da pastagem às doses de nitrogênio pode ter decorrido da fertilidade do solo, que não limitou o desempenho das plantas, e também da presença de nível razoável de matéria orgânica no solo, em torno de $2,0-2,4 \%$. Outro fator que pode ter influenciado foram as condições climáticas ocorridas no decorrer do trabalho, com períodos de alta precipitação, que podem ter provocado a lixiviação de nitrogênio ou perdas por denitrificação (Saibro \& Silva, 1999), pois o ambiente no qual a pastagem se encontrava se manteve encharcado por longos períodos, em razão das chuvas.

A taxa de acúmulo média, 31,52 kg/ha de MS/dia, foi superior à relatada por Vizzotto (1999), 19,99 kg/ha de MS/dia, que aplicou $60 \mathrm{~kg} / \mathrm{ha}$ de $\mathrm{N}$ na mesma área experimental, e inferior à de 55,6 kg de MS/ha/dia observada por Roso et al. (1999), em mistura de aveia + azevém, em áreas elevadas, com adubação de cobertura de $175 \mathrm{~kg} / \mathrm{ha}$ de $\mathrm{N}$.

A produção total de forragem, produto da taxa de acúmulo pelo número de dias de cada período, seguiu o mesmo comportamento. Não houve diferença $(\mathrm{P}>0,05)$ na produção total de forragem entre os níveis de nitrogênio e a suplementação em ambos os anos, com média de $5.142 \mathrm{~kg} / \mathrm{ha}$ de MS, em 11 dias de utilização da pastagem, e porcentagem de matéria seca na massa de forragem de 22,5\% no ano de 2000, enquanto, no ano seguinte, a média foi de $4.725 \mathrm{~kg} / \mathrm{ha} \mathrm{de}$ MS, em um período de 85 dias de utilização, com porcentagem de MS de 23,8\%.

O teor de PB na simulação de pastejo não apresentou diferença $(\mathrm{P}>0,05)$ entre os tratamentos no Ano 1, apresentando média de 14,5\% de PB (Tabela 2), o que difere dos dados encontrados por Soares, (1999) que relatou aumento linear da \%PB na massa de forragem e simulação de pastejo, com aumento da dose de nitrogênio de 0 a $450 \mathrm{~kg} / \mathrm{ha}$ de N. Lupatini et al. (1998) também citaram avanço linear na \%PB, que variou de 13,17 a 22,24\%, na mistura de aveia preta com azevém, ao utilizarem 0 a $300 \mathrm{~kg} / \mathrm{ha}$ de $\mathrm{N}$, respectivamente. Estes dados reforçam a hipótese de que houve pouco aproveitamento pela pastagem do nitrogênio aplicado, pois as condições de excesso de precipitação provavelmente provocaram sua perda.

Houve diferença entre os períodos avaliados $(\mathrm{P} \leq 0,05)$, sendo que a \% PB foi superior no início do ciclo de pastejo, o que está de acordo com os resultados obtidos por Lupatini et al. (1998), utilizando mistura de aveia preta com azevém e Roso et al. (1999), com azevém. Por outro lado, Restle et al. (2000), em estudo envolvendo a mistura de aveia preta e azevém, verificaram aumento da \%PB do primeiro para o terceiro período de pastejo, 
Tabela 2 - Teor de proteína bruta (\%PB) da simulação de pastejo na pastagem de azevém submetida a doses de nitrogênio sob lotação contínua com bovinos de corte recebendo diferentes níveis de suplementação energética

Table 2 - Crude protein content $(\% C P)$ of a simulated grazing of ryegrass pasture with different nitrogen levels with beef steers fed diets with different levels of energy supplementation, under a continuous stocking rate

\begin{tabular}{l} 
Nível \\
Level \\
\hline
\end{tabular}

com posterior decréscimo. O maior valor de proteína bruta observado no primeiro período está relacionado à maior porcentagem de folhas encontrada no início do desenvolvimento da pastagem, mas também pode ser reflexo do melhor aproveitamento das aplicações de nitrogênio realizadas no mês de julho (17/07 e 28/07), em função das melhores condições de precipitação e insolação verificadas neste mês.

No Ano 2, houve diferença $(\mathrm{P} \leq 0,05)$ entre os níveis $230 \mathrm{~N}+1,0 \mathrm{~S}$ e $80 \mathrm{~N}+0,0 \mathrm{~S}$, que apresentaram teor de $\mathrm{PB}$ de $19,8 \%$ e $15,6 \%$, respectivamente. A maior $\%$ PB observada em $230 \mathrm{~N}+1,0 \mathrm{~S}$ pode ser explicada pela maior dose de nitrogênio empregada nesse tratamento. Comportamento semelhante foi observado por Lupatini et al. (1998) e Soares (1999), que observaram avanço linear no teor de PB com o aumento das doses de $\mathrm{N}$ em misturas forrageiras de inverno. Os valores de proteína bruta observados neste experimento foram superiores aos observados por Vizzotto (1999), ao avaliarem azevém+trevo branco+cornichão, em área de várzea, e semelhantes aos encontrados por Lupatini et al. (1998) em pastagem de aveia e azevém com $150 \mathrm{~kg} / \mathrm{ha}$ de N. Por outro lado, Roso \& Restle (2000), encontraram valores médios em torno de $25 \%$ de PB em misturas de gramíneas de estação fria, o que evidencia a pequena resposta obtida no teor de proteína bruta da pastagem frente à adubação nitrogenada.

Cabe ressaltar que os níveis de PB observados estão acima dos recomendados pelo NRC (1996) para dietas desta categoria animal, com exceção do último período do Ano 1, que apresentou valores inferiores, podendo comprometer o desempenho animal. Silva et al. (2002) observaram que o teor de PB da dieta influencia positivamente o ganho médio diário de peso vivo de bovinos na fase de recria, quando estudaram níveis de até $18 \%$ de PB na dieta desta categoria animal.

Os valores de \%DIVMO da simulação de pastejo não apresentaram diferença significativa $(\mathrm{P}>0,05)$ entre os tratamentos utilizados, apresentando médias de $53,3 \%$ e 54,2\% para os Anos 1 e 2, respectivamente. Valores semelhantes foram encontrados por Restle et 
al. (1998), ao aplicarem $200 \mathrm{~kg} / \mathrm{ha}$ de $\mathrm{N}$ em pastagens de aveia mais azevém e também por Soares et al. (1999), usando $200 \mathrm{~kg} / \mathrm{ha}$ de $\mathrm{N}$ no mesmo tipo de pastagem.

O custo total de produção apresentou valores de US\$545,52, US\$395,24 e US\$221,09/ha para os níveis $300 \mathrm{~N}+0,8 \mathrm{~S}, 200 \mathrm{~N}+0,4 \mathrm{~S}$ e $100 \mathrm{~N}+0,0 \mathrm{~S}$, respectivamente, no Ano 1 (Tabela 3). No Ano 2, estes custos foram de US $\$ 359,96$, US $\$ 287,39$ e US\$200,92/ha para $230 \mathrm{~N}+1,0 \mathrm{~S}, 155 \mathrm{~N}+0,5 \mathrm{~S}$ e $80 \mathrm{~N}+0,0 \mathrm{~S}$, respectivamente, e os custo fixos somaram US\$101,63/ha no Ano 1 e US\$106,63/ha, no Ano 2. A adubação nitrogenada e o grão de milho foram os insumos que mais contribuíram para a elevação dos custos nos dois anos analisados, representando 67,$64 ; 55,34$ e 28,39\% do custo total para $300 \mathrm{~N}+0,8 \mathrm{~S}, 200 \mathrm{~N}+0,4 \mathrm{Se} 100 \mathrm{~N}+0,0 \mathrm{~S}$, respectivamente, e 54,$67 ; 43,23$ e $24,99 \%$ do custo total para os níveis $230 \mathrm{~N}+1,0 \mathrm{~S}, 155 \mathrm{~N}+0,5 \mathrm{~S}$ e $80 \mathrm{~N}+0,0 \mathrm{~S}$, respectivamente. Restle et al. (2000) também observaram que a adubação nitrogenada foi o item que mais contribuiu no custo de produção da pastagem, chegando a 47,56\% do custo total.

As maiores rendas brutas foram observadas nos tratamentos em que utilizaram-se doses mais elevadas de nitrogênio e suplementação energética, como conseqüência do maior ganho de peso vivo por hectare obtido nos tratamentos que mantiveram maior taxa de lotação (Tabela 3). No primeiro ano, a maior renda líquida foi observada em $100 \mathrm{~N}+0,0 \mathrm{~S}$ com US\$142,54/ha, seguidodo $200 \mathrm{~N}+0,4 \mathrm{~S}$, com US $\$ 102,94 /$ ha. Onível $300 \mathrm{~N}+0,8$ S apresentou renda líquida negativa (-18,71 US\$/ha), mesmo com maior produção por hectare, que, no entanto, não foi suficiente para cobrir os custos das maiores doses de nitrogênio e suplementação utilizadas. No segundo ano, a renda líquida observada foi negativa em todos os tratamentos testados.

As rendas líquidas neste experimento são inferiores às encontradas por Restle et al. (1999), que trabalharam, em áreas elevadas, com misturas de gramíneas de estação fria com adubação de cobertura de $175 \mathrm{~kg} / \mathrm{ha} \mathrm{de}$ NeobtiveramUS\$153,76/haparaamisturade trevoeazevém, US\$124,16/ha para aveia e azevém e US\$139,33/ha para trevo, aveia e azevém.

No Ano 1, a maior relação RB/CT $(1,64)$ foi obtida no nível $100 \mathrm{~N}+0,0 \mathrm{~S}$, valor que representa quanto o produtor receberá para cada US\$ investido no sistema de produção. A maior produtividade alcançada nos demais tratamentos não foi suficiente para alcançar o mesmo benefício atingido com a utilização de menores níveis de insumos. Frizzo et al. (2003) também observaram maior relação $\mathrm{RB} / \mathrm{CT}$ para o tratamento sem suplementação quando comparado com $0,7 \%$ e $1,4 \%$ do PV em pastagem cultivada de inverno, alcançando uma relação $\mathrm{R}$ \$1,90; $\mathrm{R}$ \$1,54 e R \$1,16, respectivamente. Restle et al. (2000), trabalhando com $200 \mathrm{~kg} / \mathrm{ha}$ de $\mathrm{N}$ em pastagem de azevém e aveia obtiveram relação $\mathrm{RB} / \mathrm{CT}$ de 1,19 e 1,01 com a aplicação de uréia e sulfato de amônia como fontes de $\mathrm{N}$, respectivamente. Estes retornos econômicos foram menores que os obtidos neste experimento.

Tabela 3 - Custo total $(C T)$, renda bruta $(R B)$, receita líquida (RL), relação renda bruta/custo (RB/CT) (US\$/ha), taxa de lotação (TL) (UA/ha) e ganho de peso vivo por ha (GPV) (GPV, kg/ha) de bovinos de corte recebendo diferentes níveis de suplementação energética em pastagem de azevém submetida a doses de nitrogênio

Table 3 - Total cost (TC), gross net (GN), net income (NI), gross net/cost ratio, stocking rate ( $\mathrm{kg}$ of $L W$ / ha) and weight gain/ha ( $\mathrm{kg} / \mathrm{ha}$ ) of beef steers fed diets with different levels of energy supplementation, in a ryegrass pasture with different nitrogen levels

\begin{tabular}{|c|c|c|c|c|c|c|}
\hline Tratamento & CT & $\mathrm{RB}$ & $\mathrm{RL}$ & $\mathrm{RB} / \mathrm{CT}$ & $\mathrm{TL}$ & GPV \\
\hline \multirow[t]{2}{*}{ Treatment } & $T C$ & $G N$ & $N I$ & $G N / C R$ & $S R$ & $W G$ \\
\hline & \multicolumn{6}{|c|}{$2000^{1}$} \\
\hline $300 \mathrm{~N}+0,8 \mathrm{~S}$ & 545,52 & 526,81 & $-18,71$ & 0,97 & $1418 \mathrm{~A}$ & $763,5 \mathrm{~A}^{3}$ \\
\hline $200 \mathrm{~N}+0,4 \mathrm{~S}$ & 395,24 & 498,18 & 102,94 & 1,26 & $1400 \mathrm{~A}$ & $722,0 \mathrm{~A}$ \\
\hline $100 \mathrm{~N}+0,0 \mathrm{~S}$ & \multicolumn{6}{|c|}{$2001^{2}$} \\
\hline $230 \mathrm{~N}+1,0 \mathrm{~S}$ & 359,96 & 227,76 & $-132,20$ & 0,63 & 1046A & $438,0 \mathrm{~A}$ \\
\hline $155 \mathrm{~N}+0,5 \mathrm{~S}$ & 287,39 & 208,00 & $-79,39$ & 0,72 & $1054 \mathrm{~A}$ & $400,0 \mathrm{~A}$ \\
\hline $80 \mathrm{~N}+0,0 \mathrm{~S}$ & 200,92 & 132,60 & $-68,32$ & 0,66 & $735 B$ & $255,0 \mathrm{~B}$ \\
\hline
\end{tabular}

\footnotetext{
1 Preço por kg de PV do boi em 11/2000 (US\$ 0,69).

${ }^{2}$ Preço por $\mathrm{kg}$ de PV do boi em 10/2001 (US\$ 0,52).

${ }^{3}$ Médias seguidas de letras distintas na linha diferem $(P<0,05)$ entre si pelo teste Tukey.

1 Price/kg LW of cattle at 2000/11 (US\$.69).

2 Price/kg LW of cattle at 2001/1 (US\$.52).

${ }^{3}$ Means followed by different letters, within a row, differ $(P<.05)$ by Tukey test.
} 
Em 2001, a relação RB/CT foi de 0,63; 0,72 e 0,66 para $230 \mathrm{~N}+1,0 \mathrm{~S}, 155 \mathrm{~N}+0,5 \mathrm{~S}$ e $80 \mathrm{~N}+0,0 \mathrm{~S}$, respectivamente. Diante destes resultados, deve-se ressaltar a importância da eficiência na implantação do azevém como planta forrageira neste ecossistema, que deve ser feita em época que permita seu estabelecimento antes do inverno, quando, geralmente, tem-se condições adversas ao estabelecimento das plantas, como por exemplo, excesso hídrico. Essa prática visa garantir a produção de forragem de melhor valor nutritivo que permita maiores ganhos por animal e por área e, também, maior período de utilização da pastagem.

A viabilidade do uso de forrageiras de inverno em ambiente de várzea para produção animal foi comprovado por Marchezan et al. (2001), em análise econômica de três anos de utilização de pastagem de inverno com diferentes níveis de adubação, em que observaram renda líquida média em US $\$ /$ ha de 50,$30 ; 82,50$ e 29,30, respectivamente, para os tratamentos com 150, 100 e $50 \%$ da recomendação oficial de adubação.

Um aspecto importante para o sucesso de utilização das pastagens de estação fria em área de várzea é a forma de implantação da pastagem. $\mathrm{O}$ azevém estabelecido pelo processo de sobre-semeadura, sem dessecar as espécies presentes na área ou mesmo na forma de plantio direto ou cultivo mínimo, oferece algumas dificuldades para o seu desenvolvimento inicial, como o pequeno contato da semente com o solo, aumentando o período para germinação e tornando-o mais vulnerável a perdas de sementes, como foi o caso observado nos dois anos do experimento, podendo comprometer o estabelecimento das plântulas, tornando necessária, muitas vezes, a ressemeadura, que, além de aumentar os custos, ocorre fora da melhor época de estabelecimento da pastagem.

Outro fator importante é a necessidade de utilizar maior quantidade de nitrogênio, para permitir que o azevém venha a competir com as espécies presentes na área, ou para compensar o $\mathrm{N}$ imobilizado na decomposição do material que foi dessecado. Há ainda outra variável a se considerar, que são as condições de temperatura no inverno. Se as temperaturas forem acima do normal para o período, as espécies nativas presentes se desenvolvem com maiores taxas de crescimento, proporcionando forte competição com o azevém, que não se estabelece adequadamente, fato observado no Ano 2 do experimento.

\section{Conclusões}

No ecossistema várzea, o aumento das doses de adubação nitrogenada em cobertura, associado a níveis de suplementação energética, embora proporcionem acréscimo na lotação animal, não afeta a taxa de produção de massa seca, os teores de proteína bruta e a digestibilidade in vitro da matéria orgânica da forragem, resultando em menor renda líquida.

O resultado esperado do retorno em relação ao capital investido depende da eficiência da técnica, considerando o sucesso na implantação da gramínea forrageira.

\section{Literatura Citada}

ASSOCIATION OF OFFICIAL ANALYTICAL CHEMISTS AOAC. Official methods of analysis. 14.ed. Washington, D.C.: 1984. 1141p.

ASSMANN, A.L.; ASSMANN, T.S.; MORAES, A. et al. Efeito de diferentes níveis de suplementação com milho no ganho de peso de novilhos em pastejo. In: REUNIÃO DA SOCIEDADE BRASILEIRA DE ZOOTECNIA, 36., 1999, Porto Alegre. Anais... Porto Alegre: Sociedade Brasileira de Zootecnia, 1999. CD ROM. Forragicultura. Avaliação com animais. FOR-024.

COELHO, R.W.; REIS, J.C.L. Produtividade de diversas consorciações entre gramíneas e leguminosas em planossolo no litoral sul do Rio Grande do Sul. In: REUNIÃO DA SOCIEDADE BRASILEIRA DE ZOOTECNIA, 37., 2000, Viçosa, MG. Anais... Viçosa, MG: Sociedade Brasileira de Zootecnia, 2000. CD-ROM. Forragicultura. FOR2-043.

COMISSÃO DE FERTILIDADE DO SOLO- RS/SC. Recomendação de adubação e de calagem para os estados do Rio Grande do Sul e de Santa Catarina. 3.ed. Pelotas. SBPSNúcleo Regional Sul, 1999. 223p.

FRIZZO, A.; ROCHA, M.G.; RESTLE, J. et al. Suplementação energética na recria de bezerras de corte mantidas em pastagem de inverno. Revista Brasileira de Zootecnia, v.32, n.3, p.632-642, 2003.

GARDNER, A.L. Técnicas de pesquisa em pastagem e aplicabilidade de resultados em sistemas de produção. Brasília. EMBRAPA-CNPGL, 1986. 197p.

GOMES, J.F.; REIS, J.C.L. Produção de forrageiras anuais de estação fria no litoral Sul do Rio Grande do Sul. Revista Brasileira de Zootecnia, v.28, n.4, p.668-674, 1999.

KLOSTER, A.M.; AMIGONE, M.A. Utilización de verdeos invernales bajo pastoreo en produccion de carne. Revista Argentina de Producción Animal, v.19, n.1, p.47-56, 1999.

LUPATINI, G.C.; RESTLE, J.; CERETA, M. et al. Avaliação da mistura de aveia preta e azevém sob pastejo submetida a níveis de nitrogênio. Pesquisa Agropecuária Brasileira, v.33, n.11, p.1939-1943, 1998.

MARCHEZAN, E.; DIFANTE, G.S.; SEGABINAZZI, T. et al. Retorno econômico da produção de bovinos de corte em área de várzea sistematizada cultivada com pastagem de inverno em níveis de adubação. In: CONGRESSO BRASILEIRO DE ARROZ IRRIGADO, 2., 2001, Porto Alegre. Anais... Porto Alegre: Instituto Riograndense do Arroz, 2001. p.751-753. 
MARINO, M.A.; MAZZANTI, A.; ECHEVERRÍA, H.E. et al. Fertilización nitrogenada de cultivos forrajeros invernales. 1. Revista Argentina de Producción Animal, v.16, p.248249, 1996. (Suplemento 1)

MAZZANTI, A.; WADE, M.H.; GARCIA, S.C. Efecto de la fertilización nitrogenada en invierno sobre el crecimiento y la composicion quimica del forraje de raigras anual. Revista Argentina de Producción Animal, v.17, n.1, p.25-32, 1997.

MORAES, A. de; MOOJEN, E.L.; MARASCHIN, G.E. Comparação de métodos de estimativa de taxa de crescimento em uma pastagem submetida a diferentes pressões de pastejo. In: REUNIÃO DA SOCIEDADE BRASILEIRA DE ZOOTECNIA, 27., 1990, Campinas. Anais... Campinas: Sociedade Brasileira de Zootecnia, 1990. p.332.

NATIONAL RESEARCH COUNCIL - NRC. Nutrient requirements of beef cattle. 7.ed. Washington, D.C.: National Academy Press, 1996. 242p.

RESTLE, J.; ROSO, C.; SOARES, A.B. Produção animal e retorno econômico em misturas de gramíneas anuais de estação fria. Revista Brasileira de Zootecnia, v.28, n.2, p.235-243, 1999.

RESTLE, J.; LUPATINI, G.C.; ROSO, C. et al. Eficiência e desempenho de categorias de bovinos de corte em pastagem cultivada. Revista Brasileira de Zootecnia, v.27, n.2, p.397-404, 1998.

RESTLE, J.; ROSO, C.; SOARES, A. B. et al. Produtividade animal e retorno econômico em pastagem de aveia preta mais azevém adubada com fontes de nitrogênio em cobertura. Revista Brasileira de Zootecnia, v.29, n.2, p.357-364, 2000.

ROSO, C.; RESTLE, J. Aveia preta, triticale e centeio em mistura com azevém. Produtividade animal e retorno econômico. Revista Brasileira de Zootecnia, v.29, n.1, p.85-93, 2000.

ROSO, C.; RESTLE, J.; SOARES, A.B. et al. Produção e qualidade de forragem da mistura de gramíneas anuais de estação fria sob pastejo contínuo. Revista Brasileira de Zootecnia, v.28, n.3, p.459-467, 1999.
SAIBRO, J.C.; SILVA, J.L.S. Integração sustentável do sistema arroz $\mathrm{x}$ pastagens utilizando misturas forrageiras de estação fria no litoral norte do Rio Grande do Sul. In: CICLO DE PALESTRAS EM PRODUÇÃO E MANEJO DE BOVINOS DE CORTE, 4., 1999, Canoas. Anais... Canoas: ULBRA, 1999. p.27-55.

SANTINI, F.J.; ELIZALDE, J.C. Utilización de granos en la alimentacion de ruminantes. Revista Argentina de Producción Animal, v.13, n.1, p.39-60, 1993.

STATISTICAL ANALYSES SYSTEM - SAS. Statistical analysis system user's guide. Version 6.08. Cary: 1997. $1014 p$.

SILVA, F.F.; VALADARES FILHO, S.C.; ITAVO, L.C.V. et al. Desempenho produtivo de novilhos Nelore, na recria e na engorda, recebendo dietas com diferentes níveis de concentrado e proteína. Revista Brasileira Zootecnia, v.31, n.1, p.492-502, 2002 (Suplemento).

SOARES, A.B. Produção animal em pastagem de triticale (Xtriticosecale) mais azevém (Lolium multiflorum) submetida a níveis de adubação nitrogenada. Santa Maria: Universidade Federal de Santa Maria, 1999. 185p. Dissertação (Mestrado em Zootecnia) - Universidade Federal de Santa Maria, 1999.

VIZZOTTO, V.R. Forrageiras de inverno sob pastejo em solo de várzea sistematizado, submetidos a níveis de adubação. Santa Maria: Universidade Federal de Santa Maria, 1999. 74p. Dissertação (Mestrado em Agronomia) Universidade Federal de Santa Maria, 1999. 